American Journal of Dermatological Research and Reviews (ISSN:2638-1893)

\title{
Single Oral Dose of Ivermectin as a New Therapeutic Trial for Contacts of Patients with Scabies
}

\section{Khalifa E. Sharquie ${ }^{1}$, Adil A. Noaimi ${ }^{2}$, Riyam A. Flayyih ${ }^{3}$ \\ ${ }^{1}$ Professor, MD, PhD, FRCP Edin, Department of Dermatology, College of Medicine, University of Baghdad. Iraqi and Arab Board for Dermatology and Venereology, Baghdad Teaching Hospital, Medical City, Baghdad, Iraq. ${ }^{2}$ Professor, MD, DDV, FICMS, Department of Dermatology, College of Medicine, University of Baghdad. Iraqi and Arab Board for Dermatology and Venereology, Baghdad Teaching Hospital, Medical City, Baghdad, Iraq. ${ }^{3} \mathrm{MD}$, Center of Dermatology; Baghdad Teaching Hospital; Medical City, Baghdad, Iraq.}

\section{ABSTRACT}

Background: Scabies is one of the common epidemic and endemic diseases worldwide. Many topical therapeutic modalities for scabies are available. Topical ivermectin has been used effectively in treatment of scabies but there is no oral effective therapy that prevents contacts to get scabies.

Objective: To evaluate the effectiveness of oral ivermectin in prevention of scabies contacts to get scabies.

Patients and Methods: The study is a single-blinded therapeutic study that was conducted in the Center of Dermatology, Baghdad Teaching Hospital, Baghdad, Iraq during the period from April 2018 through October 2019.Two hundred sixty healthy scabies contacts were included in this study, their ages ranged from 5-60 years with a mean \pm SD of $19.3 \pm 1.9$ years. All these contacts were screened for active scabies and they were all free. The contacts of scabies were treated by ivermectin tablet 200 microgram per $\mathrm{kg}$ as a single dose after 2 hours from dinner. They were seen regularly after 4 weeks to be re-examined and to record any scabies and drug side effects.

Results: The response after four weeks of single dose therapy of healthy contacts showed that 245 (94\%) from 260 were free of scabies and only 15(6\%) contacts showed infection with scabies and this was statistically significant Chi-square $(\chi 2=148$, P-value less than 0.00000001 . No any side effects were noticed in any treated contacts.

Conclusion: Oral single ivermectin dose is an effective therapy to prevent scabies contacts to get infection. It an easy method of prevention which is very useful in condition of scabies outbreaks and epidemics to stop the rapid spread of the disease.

Keywords: scabies, oral ivermectin, single dose, contacts.

*Correspondence to Author:

Riyam A. Flayyih

MD, Center of Dermatology; Baghdad Teaching Hospital; Medical City, Baghdad, Iraq.

How to cite this article:

Khalifa E. Sharquie, Adil A. Noaimi, Riyam A. Flayyih. Single Oral Dose of Ivermectin as a New Therapeutic Trial for Contacts of Patients with Scabies. American Journal of Dermatological Research and Reviews, $2020,3: 26$

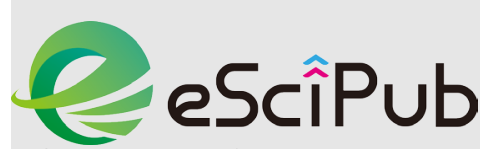

eSciPub LLC, Houston, TX USA. Website: https://escipub.com/ 


\section{Introduction}

Human scabies is an intensely pruritic skin infestation caused by the host-specific mite, Sarcoptes scabiei var hominis an arthropod of the order Acarina. ${ }^{1}$ Scabies was added to the WHO list of neglected tropical diseases in 2013 and is estimated to affect more than 130 million people globally at any time. ${ }^{2}$ The infection is endemic in many impoverished communities, but prevalence rates vary widely; seasonal outbreaks and documented peaks during times of war are probably related to crowding and population movements. ${ }^{3}$ Scabies is endemic disease in Iraq since 1980s and from now and then there have been many outbreaks of this disease. ${ }^{4,5}$ Early scabies can be difficult to diagnose for even the most experienced physicians. ${ }^{6}$

There are many topical therapeutic options that has been used in treatment of scabies like gamma-benzene-hexachloride (Lindane 1\%), benzyl Benzoate 25\%, crotamiton $10 \%$, $\%$, permethrin $5 \%$, malathion liquid $(0.5 \%)$, thiabendazole and ivermectin cream $1 \%$, which differ in mechanism of action, duration of application, cost effectiveness, relapse and recurrence rate ${ }^{7}$.

Ivermectin was approved in 2002 as a drug to treat intestinal strongyloidiasis. In August 2006, the indication for scabies was added, making it the only oral medication approved for scabies. Ivermectin is a macro cyclic lactone produced by Streptomyces avermitilis. Although it is still not FDA-approved for scabies, ivermectin represents an effective treatment for this and other ectoparasitic infestations. ${ }^{8,9}$ By blocking transmission across nerve synapses that utilize glutamate ory-aminobutyric acid (GABA), ivermectin causes paralysis of peripheral motor function in insects and acarines. ${ }^{8,9}$

Although GABA and glutamate are neurotransmitters within the human cerebral cortex after early infancy, the blood-brain barrier prevents CNS penetration of the drug. Still ivermectin is not recommended for children who weigh <33pounds $(15 \mathrm{~kg})$, pregnant women (category $\mathrm{C}$ ), or breastfeeding mothers. ${ }^{10}$ Ivermectin is contraindicated in patients with an allergy to ivermectin and CNS disorders

In clinical studies, ivermectin has proven to be extremely safe as over 18 million people $>5$ years of age have been treated annually with ivermectin in the WHO Onchocerciasis Eradication Program. An increased death rate in elderly patients who received ivermectin in a single retrospective study ${ }^{11}$ was determined to be causally unrelated to the medication as was confirmed by the WHO, medical examiners, and the scientific community.

Oral ivermectin is easier to administer than traditional topical scabicides, thus facilitating treatment of large populations. A single dose of oral ivermectin 200 micrograms $/ \mathrm{kg}$ of body weight is effective mode of therapy. ${ }^{2,}, 12$ Ivermectin may not sterilize scabies eggs and a second dose given after one week has been shown to increase the response ${ }^{13}$.

Ivermectin, when used in treatment of filariasisis, has been shown to be apparently a safe drug with a low incidence of adverse effects such as headache, pruritus, pains in the joints and muscles, fever, maculo-papular rash, and lymphadenopathy. Whether these symptoms are directly related to drug action or secondary to destruction of the filariae remains unclear. ${ }^{14}$

Accordingly, it is easy to treat patients with scabies by different topical therapies but very difficult or sometime impossible to treat contacts using topical agents especially when these contacts are huge number. So, the aim of the present work is to evaluate the effectiveness of single oral dose of ivermectin as a preventive measure for contacts of patients with scabies.

\section{Patients and Methods}

This is a single, blinded, therapeutic study to evaluate the effectiveness of oral ivermectin as a preventive agent of scabies for contacts persons with scabietic patients. Two hundred sixty of contacts of patients with scabies were enrolled in this study which was conducted in the 
Center of Dermatology, Baghdad Teaching Hospital, Baghdad, Iraq during the period from April 2018 through October 2019.

All contacts of scabies were healthy without any symptoms and signs of scabies.

Their ages ranged from 5-60 years with a mean \pm SD of $19.3 \pm 1.9$ years. The number of contacts in each family was ranged from 1-7 members.

\section{The exclusion criteria were as follow:}

1 -contacts less than 5 year of age.

2-Pregnant and lactating contact women.

3-Allergy to Ivermectin.

4-Any CNS disorders.

Formal consent was taken from each contact persons after full explanation about the goal and nature of the present study. Also, ethical approval was given by the Scientific Council of Dermatology and Venereology-Arab Board for Medical Specializations.

The contacts were treated by ivermectin tablet 200 microgram per $\mathrm{kg}$ as a single oral dose.

Ivermectin tablet as Avoctin $\AA$ tablet $6 \mathrm{mg}$ manufactured for Laboratory Innotech International (Chouzy, France).

The contact individuals were seen after 4weeks of single oral ivermectin to be evaluated and record any active scabies. Also to report any significant side effects.

Statistical analysis: Descriptive statistics (Measures of central tendencies and dispersion; like mean and standard deviation) were used together with analytic statistics (Chi-square) using EPI-Info version 20.

\section{Results}

The response after four weeks of single dose therapy of healthy contacts showed that 245 $(94 \%)$ from 260 were free of scabies and only $15(6 \%)$ contacts showed infection with scabies and this was statistically significant Chi-square $(\chi 2)=148$, P-value less than 0.00000001 . No any side effects were noticed in any treated contacts.

\section{Discussion}

Scabies is one of the commonest endemic diseases in the world, particularly in the developing world ${ }^{15}$. There are many topical therapeutic options that has been used in treatment of scabies like gamma-benzenehexachloride (Lindane 1\%), benzyl Benzoate $25 \%$, crotamiton $10 \%$, $\%$, permethrin $5 \%$, malathion liquid $(0.5 \%)$, thiabendazole and ivermectin cream $1 \%,{ }^{7}$. Recently systemic oral Ivermectin has been used in treatment of scabies but not FDA approved.

The treatment of scabies should be an easy practice as patients are suffering from severe itching that interfere with daily activities in addition that scabies is still a stigma in many countries. Accordingly these patients are ready to accept any therapy. But there is a major problem regarding contacts of patients with scabies as it is very difficult to convince these contacts to get therapy. So it is very essential to find easy treatment, simple to use and lacking side effects.

The objective of present work is to confirm the effectiveness of oral ivermectin as single dose for treatment of scabies contact.

To the best of our knowledge this is the first study in Iraq that has been carried out and the second study in the world to assess and evaluate the effectiveness of oral Ivermectin as a preventive measure in contact individuals with scabietic patients.

This study revealed that cure rate of oral ivermectin as a single dose as preventive measure in the contacts of scabies was $94 \%$ in comparison with $93.2 \%$ in another study in prison in Brazil ${ }^{16}$ which are the only study in the prophylaxis of scabies where they found that oral ivermectin at a dose of $300 \mu \mathrm{g} / \mathrm{kg}$ single dose repeated after 7 days proved effective for the treatment and prophylaxis of scabies in an infected institutional environment. But the present work using single dose was as effective as double dose. In addition, lowering dose 200 $\mu \mathrm{g} / \mathrm{kg}$ had been used compared to $300 \mu \mathrm{g} / \mathrm{kg}$ in Brazilian study. Also in the Brazil work the total number of patients was 94 and the contacts was 
29 in contrast to the present study where there were 150 patients and 260 contacts (Noaimi AA, Flayyih RA, Treatment of Scabietic Patients with Permethrin cream, Ivermectin cream, Oral Ivermectin as a comparative study: Oral Ivermectin as a preventive agent for Contacts with Patients of Scabies) is submitted to the Council of Arab Board for Health Specializations as a partial fulfillment of Arab Board for Health Specializations in Dermatology and Venereology. Oral ivermectin showed no evident side effects, so it is obviously safe oral easy therapy.

In conclusion single oral ivermectin is effective as a preventive measure for contacts of patients with scabies. Accordingly, we recommend using oral ivermectin especially in large families and in condition of outbreak and epidemic as prophylaxis and preventive maneuvers against spread of scabies infection.

\section{References}

1. Currier RW, Walton SF, Currie BJ. Scabies in animals and humans: history, evolutionary perspectives, and modern clinical management. Annals of the New York Academy of Sciences. 2011 Aug; 1230(1):E50-60.

2. Romani L, Whitfeld MJ, Koroivueta J, Kama M, Wand $\mathrm{H}$, Tikoduadua L, Tuicakau M, Koroi A, Andrews $\mathrm{R}$, Kaldor JM, Steer AC. Mass drug administration for scabies control in a population with endemic disease. New England Journal of Medicine. 2015 Dec 10; 373(24):2305-13.

3. Currie BJ, McCarthy JS. Permethrin and ivermectin for scabies. New England Journal of Medicine. 2010 Feb 25; 362(8):717-25.

4. Al-Rawi J R. Clinic-epidemiological study of scabies in Baghdad Teaching Hospital (Master Thesis in Community Medicine, College of Medicine, Al-Mustansirya University), 1990.

5. Al-Badri A A. Epidemiological and therapeutic study of scabies in Baghdad (Master thesis in Community Medicine, College of Medicine University of Baghdad), 1994.

6. Chosidow O. Scabies. New England Journal of Medicine. 2006 Apr 20; 354(16):1718-27.

7. Scott GR, Chosidow O; IUSTI/WHO. European guideline for the management of scabies, 2010.Int J STD AIDS. 2011 Jun; 22(6):301-3.

8. Meinking T, Burkhart CG, Burkhart CG, James R. Ectoparasitic diseases in dermatology: reassessment of scabies and pediculosis, pp. 77108. Advances in dermatology, vol. 15. 1999.

9. Meinking TL, Taplin D, Herminda JL, Pardo R, Kerdel FA. The treatment of scabies with ivermectin. New England Journal of Medicine. 1995 Jul 6; 333(1):26-30.

10. Workowski KA, Bolan GA. sexually transmitted diseases treatment guidelines, 2015. MMWR. Recommendations and reports: Morbidity and mortality weekly report. Recommendations and reports. 2015 Jun 5; 64(RR-03):1.

11. Barkwell R, Shields S. Deaths associated with ivermectin treatment of scabies. The Lancet. 1997; 349(9059):1144-5.

12. Marks M, Taotao-Wini $B$, Satorara L, Engelman $D$, Nasi T, Mabey DC, Steer AC. Long term control of scabies fifteen years after an intensive treatment programme. PLoS neglected tropical diseases. 2015 Dec; 9(12).

13. Usha V, Nair TG. A comparative study of oral ivermectin and topical permethrin cream in the treatment of scabies. Journal of the American Academy of Dermatology. 2000 Feb 1; 42(2):23640.

14. Roos TC, Roos S, Merk HF, Bickers DR. Pharmacotherapy of ectoparasitic infections. Drugs. 2001 Jul 1; 61(8):1067-88.

15. Fuller LC. Epidemiology of scabies. Current opinion in infectious diseases. 2013 Apr 1; 26(2):123-6.

16. Ribeiro FD, Taciro E, Guerra MR, Eckley CA. Oral ivermectin for the treatment and prophylaxis of scabies in prison. Journal of dermatological treatment.2005Jan1; 16(3):138-41. 